\title{
CODE-SWITCHING IN THE CLASSROOM: RESEARCH PARADIGMS AND
}

APPROACHES

Reference: Lin, Angel M. Y. (2008). Code-switching in the classroom: Research paradigms and approaches. In K. A. King, \& N. H. Hornberger (Eds.), Encyclopedia of language and education, 2nd Edition, Volume 10: Research methods in language and education (pp. 273-286). New York: Springer Science.

\section{CODE-SWITCHING IN THE CLASSROOM: RESEARCH PARADIGMS AND APPROACHES}

\section{$\underline{\text { Introduction }}$}

Classroom code-switching refers to the alternating use of more than one linguistic code in the classroom by any of the classroom participants (e.g., teacher, students, teacher aide). In this discussion, both code-mixing (intra-clausal/sentential alternation) and code-switching (alternation at the inter-clausal/sentential level) will be referred to by the umbrella term, code-switching, as this is also the general practice in many classroom code-switching studies. The aim of this contribution is to provide an overview of the research literature and to point towards future research directions.

\section{Early developments}

While classroom code-switching studies have been diverse, the often-quoted early studies chiefly have been conducted in North American settings in two main kinds of contexts: (1) second language contexts (e.g., ESL classrooms) and (2) bilingual education classrooms. The research methods largely drew on quantitative and functional coding analysis. Research interest has mainly been directed at two aspects: the relative quantities of first language (L1) and second language (L2) use in different activity settings, and the functional distribution of L1 and L2. Below is a review of the research methods used in some early studies.

Early studies on relative amounts of L1/L2 use across activity types and settings

This type of research has largely been conducted in North American settings with children in bilingual education programmes (e.g., Wong-Fillmore, 1980). The main emphasis of such work is to investigate whether linguistic minority children's L1 (e.g., Spanish, Chinese) and the wider, societal language (English) are given equal emphasis by calculating the relative quantities of use in the classroom (in terms of the number 
of utterances in each code or the time spent on it). Data for such studies is typically collected through class visits and observations with subsequent analysis of field notes and audio/videotapes. For instance, Wong-Fillmore (1980) found a range of L1 use depending on the degree of individualization in teacher-student interaction. In a Cantonese-English bilingual programme, the teacher spoke the least L1 (8\% of all her utterances) and the most L2 (92\%) during whole-class instruction. She spoke more L1 (28\%) during interactions with individual students in seatwork. The child chosen for observation, on the other hand, spoke much more L1 (79\%) in seatwork than during teacher-directed whole class instruction (4\% L1). This study suggests the preference for the use of L1 in less formal, more intimate participant structures.

In another study (Frohlich et al., 1985) on the communicative orientation of L2 classrooms in four different programmes in Canada (e.g., core French, French immersion, extended French with subject matter courses, ESL classrooms), teacher talk in all four programmes was found to reflect very high L2 use (96\%). However, the researchers noted that students generally used the target language only while the teacher exercised control over classroom activities. During seatwork most interaction occurred in the students' L1. Again, it seems that students show strong preference for using L1.

While the interactive sociolinguistic notion of 'participant structure' (Goffman, 1974; Heller, 2001) was not used in these early studies, they relied instead on the related notion of activity type or setting (e.g., individual seatwork, group work, whole-class instruction) as an important factor affecting the relative amounts of L1/L2 use in both studies above. In contrast, other work used functional coding systems in their analysis to develop categories of functions for which L1 is used.

\section{Early studies on functional distribution of L1/L2 use}

Many of the functional studies were conducted in bilingual content classrooms in the U.S. and only a few on second and foreign language classrooms. In these studies classroom utterances were usually coded by the observer with a functional system (e.g., Flanders, 1970) yielding frequency counts of distribution of L1 and L2 over different functional categories. For instance, in a study of based on observations of five kindergartens in Spanish bilingual programmes and using an adaptation of Flanders' Multiple Coding System, Legarreta (1977) reported on the functional distribution of Spanish (L1) and English (L2) in two different models: the Concurrent Translation (CT) and Alternative Days (AD). She found that the AD model 
generated an equal distribution of Spanish and English by teachers and children overall, with more Spanish used for "warming" and "directing" functions and English as the primary choice for disciplining children. However, in the CT model, instead of using the L1 (Spanish) of the majority of the pupils to express solidarity (warming, accepting, amplifying), the teachers and aides predominantly used English for these functions.

In another study, Milk (1981) coded teacher talk in a twelfth grade bilingual civics lesson according to eight basic pedagogical functions (e.g., informative, directive, humor-expressive) based on Sinclair and Coulthard (1975). English (L2) was found to dominate the teacher's directives $(92 \%)$ and meta-statments $(63 \%)$ while there was a greater balance between L1 and L2 in other functions (e.g., elicitation, expressive, reply, informative). In additional, Milk described the skillful manner in which the bilingual teacher employed extensive switching between Spanish and English to create humour, both as a means of social control (via the creation of a sense of solidarity) and as a way to arouse students' interest.

Guthrie (1984) used similar research methods in a study of an ESL lesson attended by 11 first-grade Cantonese-American students (ranging from limited-English proficiency to fluent). Two types of lessons were analysed: reading in English with a Cantonese-English bilingual teacher, and oral language with an English monolingual teacher. Field notes and audio-recording of six hours of lessons were obtained and coded by two bilingual observers. found that interactions of the English monolingual teacher with the limited-English-proficiency students in the oral lessons were characterized by a higher proportion of conversational acts such as 'attention-getters', 'requests for action' and 'protests', indicating a certain lack of teacher control and a frequent loss of student attention. On the other hand, while the bilingual teacher used Cantonese (L1 of the students) very rarely (less than 7\% on average) in the English reading lessons, when she did it was for a distinct reason. She told the researchers that she tried to avoid using Cantonese during these lessons and was surprised to find she has used L1 as much as she had. The functions of L1 use reported by Guthrie can be summarized as: (a) to act as a "we-code" for solidarity, (b) to clarify or check for understanding, (c) to contrast variable meanings in L1 and L2 and to anticipate likely sources of confusion for students.

So, while the functional coding approach dominated early work, in some studies (e.g., Milk, 1981; Guthrie, 1984) preliminary use of ethnographic interviews and interactional sociolinguistic methods were incorporated, a trend which continued in 
later work.

\section{$\underline{\text { Major Contributions }}$}

Many early studies seemed to have worked with the assumption that functional categories were stable, valid categories of classroom speech and that analysts could reliably assign utterances to each category. Yet the functional coding approach in early studies in fact involved a lot of sociolinguistic interpretive work on the part of the coder. This interpretive work was, however, not made explicit but taken for granted in the form of final frequency counts of L1 and L2 distributed across different functional categories.

Later studies (e.g., Lin, 1990, 1996, 1999; Merritt et al., 1992; Adendorff, 1993; Ndayipfukamiye, 1994; Polio \& Duff, 1994; Eldridge, 1996; Martin-Jones, 1995, 2001; Heller, 1999, 2001; Jacobson, 2001; Simon, 2001; Martin, 1996, 1999, 2003; Creese, 2005) have, to varying degrees, dispensed with a priori lists of functional categories and drawn on research approaches from interactional sociolinguistics and ethnography of communication (e.g., Goffman, 1974; Gumperz, 1982; 1986); conversation analysis (Sacks, 1965/1992); interpretive research paradigms; critical social theory (Bourdieu and Passeron, 1977); and critical research paradigms to study classroom code-switching (see also Li Wei, Keleen Toohey, Martin-Jones, this volume, for these or related research paradigms).

Just as interactional sociolinguistics (IS) and ethnography of communication (EC) provide the most useful analytic tools for researching and understanding code-switching in different settings in society, their concepts and methods have been drawn upon in classroom studies on code-switching. For instance, the most frequently and fruitfully used ones are: code-switching as contextualization cues (Gumperz, 1984) to signal a shift in the frame or footing (Goffman, 1974) of the current interaction (e.g., see Adendorff, 1993). Frame or footing is the definition of what is happening and it is constantly being negotiated, proposed (signaled) and re-defined by the speakers engaged in interaction. Different frames or footings that are being evoked (or signaled and proposed by a speaker) involve the simultaneous negotiation of different role-relationships and the associated sets of rights/obligations. Lin's studies (1990, 1996), for instance, drew on these interactional sociolinguistic analytic concepts to analyse code-switching in Hong Kong classrooms. Below is an example from Lin's (1996)reanalysis of Johnson's (1985) data in Hong Kong secondary schools, using IS analytic concepts. The data presentation format is as in Johnson's: 
Tape-recorder counter numbers precede utterances; bold italics indicate originally Cantonese utterances, and only teacher's utterances have been transcribed.

\section{Example (1)}

A junior secondary math teacher in Hong Kong begins his lesson in English and then breaks off and switches to Cantonese to deal with late-comers; once they are settled, he switches back to English to continue with the lesson work ("Example 1" in Johnson, 1985, p. 47):

008 Close all your text book and class work book.

\section{There are some classmates not back yet. Be quick!}

017 Now, any problem about the class work?

Johnson (1985) analyses the Cantonese utterance as an example of an informal aside done in Cantonese. While agreeing partially with this analysis, we note, however, that if it is to mark out a mere topical digression, the teacher can well have done this by means other than code-switches, e.g., intonational changes, hand-claps or pauses to bracket the aside (see example in Lin, 1990, pp. 32-36). The use of these contextualization cues (Gumperz, 1984) does not involve a violation of the institutional "use-English-only" constraint which teachers in Anglo-Chinese secondary schools in Hong Kong were well aware of. It can, therefore, be argued that what is being signalled here is not only a topical aside, but also a radical break in the English pedagogic frame and an urgent change in the teacher's concerns. The switch from English to Cantonese seems to relay to his students this implicit message, "Now I'm so annoyed by these late-comers that I have to put aside all kinds of teaching, including that of English teaching, and concentrate on one single task: that of getting you to settle down quickly! And you'd better take my command seriously as I'm single-minded in enforcing it!" This break in the English pedagogic frame to highlight a different, urgent set of concerns cannot have been achieved without the teacher's switch from English (L2) to Cantonese (L1).

The key, therefore, to understanding the implicit meanings signalled by code-switches lies in a recognition of the sociolinguistic fact that whenever Hong Kong Cantonese have something urgent and earnest to relay to one another, they do so in their shared native language; whenever Hong Kong Cantonese speak to one another in English despite their having a common native language, it is usually because of some 
institutionally given reasons, for instance, to teach and learn the English language in an English immersion classroom. When teachers want to establish a less distanced and non-institutionally defined relationship with their students, they will also find it necessary to switch to their shared native language, Cantonese.

Similar kinds of analysis drawing on IS and EC research methods are offered in Simon's (2001) study of code-switching in French-as-a-foreign-language classrooms in Thailand. Teachers are seen as code-switching for a number of purposes, among which are those of negotiating different frames (e.g., formal, institutional learning frame vs. informal friendly frame), role-relationships and identities (e.g., teacher vs. friend). Code-switching is seen as having a 'momentary boundary-levelling effect' in the classroom (Simon, 2001, 326). Whether similar effects might be achieved by code-switching in different contexts would, however, seem to depend on different sociolinguistic statuses and values associated with different codes in different societies.

In studies along this line, IS and EC analytical concepts and methods are drawn upon to analyse instances of classroom code-switching. The findings look remarkably similar across different sociocultural contexts. Code-switching is seen to be an additional resource in the bilingual teacher's communicative repertoire enabling her/him to signal and negotiate different frames and footings, role-relationships, cultural values, identities and so on in the classroom (e.g., see Merritt et al., 1992; Ndayipfukamiye, 1994). These studies have the effect of uncovering the good sense or the local rationality (or functions) of code-switching in the classroom. To summarize by drawing on the functional framework of language from Halliday (1994), code-switching can be seen as a communicative resource readily drawn upon by classroom participants (usually the teacher but sometimes also students) to achieve the following three kinds of purposes:

1. Ideational functions: Providing limited-L2-proficiency students with access to the L2-mediated curriculum by switching to the students' L1 to translate or annotate (e.g., key L2 terms), explain, elaborate or exemplify L2 academic content (e.g., drawing on students' familiar lifeworld experiences as examples to explain a science concept in the L2 textbook/curriculum). This is very important in mediating the meaning of academic texts which are written in a poorly understood language--the $\mathrm{L} 2$ of the students.

2. Textual functions: Highlighting (signalling) topic shifts, marking out transitions between different activity types or different focuses (e.g., focusing on technical definitions of terms vs. exemplifications of the terms in students' everyday life). 
3. Interpersonal functions: Signalling and negotiating shifts in frames and footings, role-relationships and identities, change in social distance/closeness (e.g., negotiating for in-group solidarity), and appealing to shared cultural values or institutional norms.

Apart from the above studies which draw on interpretive research paradigms, there is also a major trend of studies led by Monica Heller and Marilyn Martin-Jones (e.g., in their edited 2001 book, Voices of Authority: Education and Linguistic Difference), which draws on both interpretive and critical research paradigms and they relate micro interactional functions of code-switching in the classroom to larger societal issues, such as the reproduction or sometimes contestation of linguistic ideologies in the larger society (e.g., which/whose language counts as standard and valued language; which/whose language counts as inferior or not-valued language).

Heller and Martin-Jones (2001) provided some examples on how micro ethnographic studies of classroom code-switching are not actually 'micro' in their implications if we see the classroom as a discursive site for reproduction or contestation of linguistic ideologies and hierarchies. The discursive construction/negotiation of what counts as front stage and back stage (Goffman, 1974) and the legitimation of what goes on in the front stage (largely controlled and set up by the teacher) as legitimate, standard, valued language vs. what gets marginalized, reproduced as inferior, non/sub-standard language in the back stage. Usually the societal dominant L2 occupies the first position and students' L1 occupies the latter position. For instance, in Ndayipfukamiye's (2001) study of Kirundi-French code-switching in Burundi classrooms, the bilingual teacher is seen to be using Kirundi (students' familiar language) to annotate, explain and exemplify French (L2) terms and academic content. While the linguistic brokering functions of code-switching is affirmed (i.e., the value of providing students with access to the educationally dominant language, French), the linguistic hierarchy as institutionalized in the French immersion education policy in Burundi is largely reproduced in these code-switching practices.

However, not all studies are about reproduction of linguistic ideologies and practices. For instance, Canagarajah (2001) shows how ESL teachers and students in Jaffna (the northern peninsula of Sri Lanka that has been the political centre of the Tamils) negotiated hybrid identities through code-switching between Tamil and English, defying both the Tamil-only ideology in the public domains and institutions, and the English-only ideology from the ESL/TESOL pedagogical prescriptions from the West. Canagarajah argued that both teachers and students, by code-switching comfortably 
between these two languages are also constructing their bilingual cosmopolitan identities, refusing to be pigeonholed by essentializing political ideologies (of Tamil nationalism) or English-only pedagogical ideologies.

Lin (1999) also showed that by skilfully intertwining the use of L1 (Cantonese) for a story focus with the use of L2 (English) for a language focus, a bilingual teacher in a Hong Kong English language classroom successfully got her students interested in learning English and gaining confidence in reading English storybooks, and thus transforming the habitus of these working class students for whom English had been an alien language irrelevant to their daily life. Drawing on the discourse analytical methods of conversation analysis applied to educational settings (Heap, 1985), Lin (1999) offered a fine-grained analysis of how L1-L2 code-switching was built into two kinds of Initiation-Response-Feedback discourse formats to enable the teacher (Teacher D) to engage students in both enjoying the story and in learning English through this process:

Teacher D uses two different IRF formats in the following cycle in the reading lesson:

(1) Story-Focus-IRF:

Teacher-Initiation [ L1 ]

Student-Response [ L1 ]

Teacher-Feedback [ L1 ]

(2) Language-Focus-IRF:

Teacher-Initiation [ L1/L2 $]^{1}$

Student-Response [ L1/L2 ]

Teacher-Feedback [ L2 ], or use (2) again until Student-Response is in L2

(3) Start (2) again to focus on another linguistic aspect of the L2 response elicited in (2); or return to (1) to focus on the story again.

This kind of discourse practice allows the teacher to interlock a story focus with a language focus in the reading lesson. There can be enjoyment of the story, via the use of the story-focus IRF, intertwined with a language-learning focus, via the use of the language-focus IRF. We have noted above that the teacher never starts an initiation in L2. She always starts in L1. This stands in sharp contrast with the discourse practices of Teacher $\mathrm{C}$ (another teacher in the study) who always starts with L2 texts or questions in her initiations. It appears that by always starting in L1,

1. "L1/L2" denotes "L1 or L2". 
Teacher D always starts from where the student is--from what the student can fully understand and is familiar with. On the other hand, by using the language-focus IRF format immediately after the story-focus IRF format, she can also push the students to move from what they are familiar with (e.g., L1 expressions) to what they need to become more familiar with (e.g., L2 counterparts of the L1 expressions) (see Lin, 1999).

\section{$\underline{\text { Work in Progress }}$}

In this section we shall look at new research that hints at a slightly different research angle that starts to draw on research approaches from different fields such as genre analysis and English for academic purposes (EAP).

Setati, Adler, Reed and Bapao provided a mid-term report (2002) on findings from their larger ongoing study of code-switching and other language practices in Mathematics, Science and English language classrooms in South Africa. These schools had adopted a small-group inquiry teaching approach and built on notions of additive bilingualism and strategic code-switching as encouraged by the authorities. While good in their intentions, this approach might have overlooked some pitfalls in two areas:

1. The indirect, student-centred, exploratory, group-work, learning-from-talk teaching approach: This is found to be done mostly in students' L1. However, without teacher's input on scientific content (e.g., in whole-class instruction), students may suffer from a lack of input in the English academic discourses required to talk about science topics or writing extended texts in English.

2. So, some traditional teacher-fronted whole class teaching may be needed to provide the necessary L2 academic discourses to students, especially those in rural areas.

Setati et al. (2002) found that the progressive pedagogies (e.g., student-centred group work) alone did not provide the much-needed direct teaching of subject domain-specific academic discourses and English academic literacies and thus aggravated social inequalities. Setati's et al.'s (2002) report, however, did not show much analysis of how this academic discourse can be provided or inserted into the progressive teaching approaches along with the integration of some conventional pedagogies. While this report seems to be work-in-progress, it does point out the importance of drawing on research tools of genre analysis of different subject-specific academic discourses in future studies of code-switching in the classroom. In the 
next section I shall discuss why this might provide a potentially useful direction for achieving a breakthrough of our current state of affairs in researching classroom code-switching.

\section{$\underline{\text { Problems and Difficulties }}$}

Researching code-switching in the classroom, unlike researching other kinds of related classroom phenomena (e.g., classroom discourse, classroom interactions), has often been engaged in consciously or unconsciously with either apologetic or corrective motives. Given the official pedagogical principle of prescribing the use of only one language in the classroom in some contexts (e.g., in Hong Kong, Singapore, Malaysia; see Lin \& Martin, 2005; Haroon, 2005), many researchers have studied classroom code-switching practices either to seek out their 'good sense' and local rationality or to document their pitfalls or pedagogical inefficacy. These two (implicit) aims have often shaped the research questions and research approaches used in classroom code-switching studies.

Because of these (implicit) 'legitimating' concerns of researchers the studies in the literature tend to stop short of pointing ways forward for analyzing how code-switching practices can be further improved to achieve better pedagogical and social critical purposes. They tend to be descriptive rather than interventionist; i.e., they describe existing practices (either approving of or condemning them) rather than experiment with innovative ways of code-switching practices as ways both to provide access to L2 and to critique linguistic ideologies and hierarchies in the larger society and institutions. Because of the lack of critical, interventionist research questions, the majority of studies in the classroom code-switching literature tend to offer little new insight into how existing classroom code-switching can be further changed to achieve more: e.g., more of the transformation (as hinted at by Lin, 1999 and Canagarajah, 2001), and avoid the reproduction consequences (e.g., reproducing societal ideologies about linguistic hierarchies, marginalizing the students' familiar languages while privileging the dominant societal languages). The findings of the existing research literature thus seem to be variations on similar themes (as summarized above) without providing new research questions and research approaches to achieve new findings beyond what has already been known (and repeated frequently) in the literature on classroom code-switching.

Only when we begin to think beyond the binary research question of whether it is good or bad to code-switch in the classroom (or whether classroom code-switching 
has largely positive social functions or largely negative pedagogical consequences) can we liberate ourselves from the limiting research agenda of just describing the good sense or local rationality of classroom code-switching or the vice versa (e.g., describing the reproductive, negative pedagogical as well as ideological consequences).

\section{Future Directions for Research}

To the author's knowledge, there have been no published studies of the longitudinal, interventionist type. Also, most studies were conducted by a sociolinguist or a discourse analyst, usually an outsider coming into the classroom studying the interactional practices of classroom participants. As discussed here, many studies draw mainly on the interpretive research paradigms (IS, EC and CA research approaches). These limitations in existing studies make it difficult for us to know what will happen if classroom participants (e.g., teachers, students) themselves become researchers of their own classroom practices, and what will happen if they embark on systematic study of their own practices, getting a deeper understanding of their own practices through their own research and then modify their own practices with systematic action plans and study the consequences, much like the kind of action-research carried out by the teacher-researcher. Below I outline what a future study might look like in order to achieve new insights into classroom code-switching:

1. Longitudinal research: Instead of one-shot classroom video/audiotaping studies, we need to have studies that follow the same classroom for a longer period of time; e.g., a whole course, a whole semester.

2. Interventionist research agenda: We need to integrate the sociolinguistic interpretive and conversation analytic with the action-research approaches so that the teacher becomes conscious of trying out specific bilingual classroom strategies with respect to achieving specific sets of goals. We also need to build into the research design ways of ascertaining the degree to which these goals are achieved. This is similar to the mode of teacher action research (see Varghese, this volume). Close collaboration between teacher and researcher is also needed; e.g., the teacher is the researcher or there is close collaboration between the teacher and the researcher. Likewise, depending on the readiness of the students, students can also be solicited to become researchers in the study of their own bilingual classroom practices.

3. Drawing up specific goals and designing specific bilingual classroom strategies to achieve those goals: This will require the teacher and researcher to understand the specific situated needs and goals of the educational context in which they find themselves. These educational goals need to be set up with reference to the 
needs and choices of participants in specific contexts, and not taken to mean any universal set of goals.

4. Drawing on research methods of genre analysis of domain-specific academic discourses and literacies: For instance, we need to know what are the specific genre features and discourse structures of a biology course in order to design bilingual strategies to provide students with access to biology discourses through familiar everyday discourses. There will be frequent inter-weaving between academic discourses (mostly mediated in a less familiar language to the students such as the L2 or the 'standard' dialect) and students' familiar discourses (e.g., everyday life examples and experiences mediated in students' familiar language such as their L1 or a home dialect). How can the teacher provide access to the formal, academic (often L2) discourses through the informal, everyday, familiar (often L1) discourses of the students' will become a key research question.

5. To systematically study the effectiveness of different bilingual classroom strategies, it will require a carefully planned integration of different research paradigms (including interventionist action-research, interpretive, critical) and research approaches (including those from sociolinguistics, academic genre analysis, pedagogical analysis, analysis of students' spoken and written samples of academic work, plus assessment of students' mastery of academic genre features and skills in performing academic tasks using the appropriate registers).

6. Taking a holistic, contextualized approach: We need to situate the classroom in its larger socioeconomic and political contexts and to re-examine the pedagogic goals of the classroom to see if they are really serving the interests of the students. Then we need to find out/explore possible ways to achieve these goals including (but not limited to) bilingual classroom strategies. Both traditional (e.g., teacher whole-class instruction) and progressive pedagogies (student-inquiry groups) need to be used in conjunction with a consideration of which code-switching patterns can be intertwined with which pedagogical patterns and participant structures. All these require an approach that allows for try-and-see and then document and re-try another pattern and see what happens and re-design future action plans that will progressively better achieve the goals through both bilingual and other pedagogical practices.

The above suggestions might sound like an 'unholy' eclectic approach to the linguistic or research methodological purist. However, to have breakthroughs in our current state of affairs in researching classroom codes-witching, we need to be both pragmatic and flexible in our research paradigms and approaches. As code-switching is still seen as a negative practice in the classroom in many mainstream educational contexts, 
we need concrete designs of bilingual classroom strategies and research studies that can systematically develop these designs and show their effectiveness (with respect to the situated goals of the classroom). Without designing these systematic longitudinal, interventionist studies that can work on refining bilingual classroom strategies and pedagogies to achieve the goals deemed worthwhile in specific contexts, our research literature on classroom code-switching might be seen as repetitive of apologetic statements about the good sense or diverse functions of classroom participants' practices without advancing our knowledge of how they can do better what they are already doing with different degrees of success and failure, as the studies reviewed above show.

Lin, Angel M. Y. The Chinese University of Hong Kong

\section{Bibliographic References}

Adendorff, R.: 1993, Code-switching Amongst Zulu-speaking Teachers and Their

Pupils: Its Functions and Implications for Teacher Education, Language and

Education, 7, 3, 41-162.

Bourdieu, P. and Passeron, J. C. :1977, Reproduction in Education, Society and Culture, London, Sage.

Canagarajah, S.: 2001, Constructing Hybrid Postcolonial Subjects: Codeswitching in

Jaffna Classrooms, in M. Heller and M. M. Jones (eds.), Voices of Authority:

Education and Linguistic Difference, Westport, Connecticut and London, Ablex

Publishing.

Creese, A.: 2005, Teacher Collaboration and Talk in Multilingual Classrooms, Clevedon, Multilingual Matters.

Flanders, N. A.: 1970, Analyzing Teaching Behavior, Reading, Mass, Addison-Wesley. 
Frohlich, M., Spada, N. and Allen, P.:1985, Differences in the Communicative

Orientation of L2 Classrooms, TESOL Quarterly, 19(1), 27-57.

Goffman, E.: 1974, Frame Analysis, New York, Harper and Row.

Gumperz, J. J.: 1982, Discourse Strategies, London, Cambridge University Press.

Gumperz, J. J.: 1984, Ethnography in Urban Communication, in J. C. P. Auer and A.

Luzio (eds.), Interpretive Sociolinguistics: Migrants, Children, Migrant Children,

Tubingen, Narr.

Gumperz, J. J.: 1986, Interactional Sociolinguistics in the Study of Schooling, in J. C.

Gumperz (ed.), The Social Construction of Literacy, Cambridge, Cambridge

University Press.

Guthrie, L. F.: 1984, Contrasts in Teachers' Language Use in a Chinese-English

Bilingual Classroom, in J. Handscombe, R. A. Orem and B. P. Taylor (eds.), TESOL'

83: The Question of Control, 39-52.

Halliday, M. A. K.: 1994, An Introduction to Functional Grammar (second edition), London, Edward Arnold.

Haroon, H. A.: 2005, Teacher Code-switching and its Functions in Mathematics and Science Lessons, Asia Pacific Journal of Language in Education, 7, 1, 1-25.

Heap, J.L.: 1985, Discourse in the Production of Classroom Knowledge: Reading Lessons, Curriculum Inquiry, 15(3), 345-379.

Heller, M.: 1999, Linguistic Minorities and Modernity, London, Longman. 
Heller, M.: 2001, Legitimate Language in a Multilingual School, in M. Heller and M. M. Jones (eds.), Voices of Authority: Education and Linguistic Difference, Westport, Connecticut and London, Ablex Publishing.

Heller, M. and Martin-Jones, M.: 2001 (eds.), Voices of Authority: Education and Linguistic Difference, 381-402, Westport, Connecticut and London, Ablex Publishing.

Johnson, R.K.: 1985, Report of the ELTU Study of the Oral Medium of Instruction in Anglo-Chinese Secondary School Classroom. Hong Kong: Faculty of Education, University of Hong Kong.

Legarreta, D.: 1977, Language Choice in Bilingual Classrooms, Journal of Social Issues, 23, 9-16.

Lin, A.: 1990, Teaching in Two Tongues: Language Alternation in Foreign Language Classrooms, Research Report No.3, Hong Kong, City Polytechnic of Hong Kong.

Lin, A.: 1996, Bilingualism or Linguistic Segregation? Symbolic Domination, Resistance and Code-Switching in Hong Kong Schools, Linguistics and Education, $8(1), 49-84$.

Lin, A.: 1999, Doing-English-Lessons in the Reproduction or Transformation of Social Worlds? TESOL Quarterly, 33(3), 393-412.

Lin, A. and Martin, P.: 2005 (eds.), Docolonisation, Globalisation: Language-in-Education Policy and Practice, Clevedon, Multilingual Matters.

Martin, P. W.: 1996, Code-switching in the Primary Classroom: One Response to the 
Planned and Unplanned Language Environment in Brunei, Journal of Multilingual and Multicultural Development, 17, 2-4, 128-144.

Martin, P. W.: 1999, Bilingual Unpacking of Monolingual Texts in Two Primary

Classrooms in Brunei Darussalam, Language and Education, 13, 1, 38-58.

Martin, P. W.: 2003, Bilingual Encounters in the Classroom, in J-M. Dewaele, A. Housen and Li Wei (eds), Bilingualism: Beyond Basic Principles, 67-88, Clevedon, Multilingual Matters.

Martin-Jones, M.: 1995, Codeswitching in the Classroom: Two Decades of Research, in L. Milroy and P. Muysken (eds.), One Speaker, Two Languages: Cross-Disciplinary Perspectives on Code-Switching, Cambridge, Cambridge University Press.

Merritt, M., Cleghorn, A., Abagi, J. O., and Bunyi, G.: 1992, Socializing

Multilingualism: Determinants of Codeswitching in Kenyan Primary Classrooms, in C. M. Eastman (ed.), Codeswitching, 103-121, Clevedon, Multilingual Matters.

Milk, R.: 1981, An Analysis of the Functional Allocation of Spanish and English in a Bilingual Classrooms, C. A. B. E. Research Journal, 2(2), 11-26.

Ndayipfukamiye, L.: 1994, Code-switching in Burundi Primary Classrooms, in C. M. Rubagumya (ed.), Teaching and researching language in African classrooms, 79-95, Clevedon, Multilingual Matters.

Ndayipfukamiye, L.: 2001, The Contradictions of Teaching Bilingually in Postcolonial Burundi: From Nyakatsi to Maisons en Etages, in M. Heller and M. M. Jones (eds.), Voices of Authority: Education and Linguistic Difference, 101-115, Westport, Connecticut and London, Ablex Publishing. 
Polio, C. G. and Duff, P. A.: 1994, Teachers' Language Use in University Foreign Language Classrooms: A Qualitative Analysis of English and Target Language Alternation, The Modern Language Journal, 78, 3, 313-326.

Sacks, H.: 1965/1992, Lectures on Conversation, in G. Jefferson (ed.), Lectures on Conversation, Oxford and Cambridge, Blackwell.

Setati, M. , Adler, J., Reed, Y. and Bapoo, B.: 2002, Incomplete Journeys:

Code-Switching and other Language Practices in Mathematics, Science and English Language Classroom in South Africa, Language and Education, 16(2), 128-149.

Simon, D. L.: 2001, Towards a New Understanding of Codeswitching in the Foreign Language Classroom, in R. Jacobson (ed.), Codeswitching Worldwide 2, 311-342, Berlin and New York, Mouton de Gruyter.

Sinclair, J. and Coulthard, R. M.: 1975, Towards an Analysis of Discourse. London, Oxford University Press.

Wong-Fillmore, L.: 1980, Learning a Second Language: Chinese Children in the American Classroom, in J. E. Alatis (ed.), Current Issues in Bilingual Education:

Georgetown University Round Table on Languages and Linguistics, Washington, D.

C., Georgetown University Press.

\section{Keywords}

\section{Bilingual classroom strategies}

Bilingual pedagogies

Classroom code-switching

Classroom code-mixing

Language alternation in the classroom 